\title{
Flow of the Ross Ice Shelf, Antarctica, is modulated by the ocean tide
}

\author{
Kelly M. BRUNT, ${ }^{1}$ Matt A. KING, ${ }^{2}$ Helen Amanda FRICKER, ${ }^{1}$ Douglas R. MacAYEAL ${ }^{3}$ \\ ${ }^{1}$ Institute of Geophysics and Planetary Physics, Scripps Institution of Oceanography (SIO), \\ University of California-San Diego, La Jolla, California 92093-0225, USA \\ E-mail: kbrunt@ucsd.edu \\ ${ }^{2}$ School of Civil Engineering and Geosciences, Cassie Building, Newcastle University, Newcastle upon Tyne NE1 7RU, UK \\ ${ }^{3}$ Department of Geophysical Sciences, University of Chicago, 5734 South Ellis Avenue, Chicago, Illinois 60637, USA
}

\begin{abstract}
The ice streams feeding the Ross Ice Shelf, Antarctica, have large tidally modulated (sinusoidal and stick-slip) flow, but the interaction with the ice shelf is poorly understood. We show that the flow of the Ross Ice Shelf front, up to $\sim 650 \mathrm{~km}$ from the ice streams, exhibits smooth, sinusoidal motions corresponding to tidal modulation. These observations suggest a possible linking of the ice shelf with the ice streams to form a unified system that responds to small perturbations in stresses associated with ocean tides. If this is the case, the presence of the sinusoidal motion but the absence of stick-slip motion suggests there is damping of very high-frequency signals. The dissimilar signatures of the motions observed in the ice streams and at the front of the ice shelf present challenges to model development aimed at understanding the dynamics of coupled ice-stream/ice-shelf flow and the movement of ice across grounding lines.
\end{abstract}

\section{INTRODUCTION}

Geodetic global positioning system (GPS) studies have recorded vertical motion of ice shelves and their grounding zones in response to ocean tidal forcing (Vaughan, 1995). Recent studies on the Brunt Ice Shelf and the Mertz Glacier Tongue, Antarctica, have also linked variations in horizontal motion to ocean tides (Doake and others, 2002; Legrésy and others, 2004). Diurnal- and subdiurnal-scale time variations of the horizontal flow of ice streams and small ice shelves, observed by GPS, have led to several important insights into how these systems function. For example, Anandakrishnan and others (2003) used the upstream amplitude decay of diurnal variations in the flow on Bindschadler Ice Stream (formerly Ice Stream D) of the Siple Coast to estimate the properties of subglacial resistance. Also on the Siple Coast, Wiens and others (2008) used a combination of GPS and seismic data to examine the twice-daily stick-slip behavior of Whillans Ice Stream (formerly Ice Stream B) to deduce both the mechanism for glacial earthquakes observed teleseismically and to gain an understanding of friction associated with certain subglacial sticky spots, i.e. the basal asperity on which the ice stream is 'stuck' prior to each slip phase of its motion. Similar temporal variations in horizontal flow have been observed on Rutford Ice Stream, which feeds the Ronne Ice Shelf. Gudmundsson (2006) observed a 2 week flow modulation over a 7 week GPS campaign. Murray and others (2007) reported an unprecedented 2 year field campaign of GPS measurements and found horizontal flow modulations causally tied to the ocean tides, ranging from semi-diurnal constituents all the way up to annual period constituents.

Given concerns about the stability of the West Antarctic ice sheet (Mercer, 1968), studies of temporal variation in the flow of the Siple Coast and Rutford Ice Stream strive to gain a better understanding of ice-flow dynamics and its sensitivity to external forcings. A key question motivated by these recent discoveries about ice-stream flow is: to what extent are such diurnal- and subdiurnal-scale variations evident in the flow of the large ice shelves that are fed by these ice streams and what does this suggest about the coupling between floating and grounded ice? To address this question, we conducted a field program in the austral summer of 2005, during which GPS data were collected simultaneously from three stations near the calving front of the Ross Ice Shelf. The GPS data collected contained important information about the horizontal flow of the ice shelf, which we describe in this paper.

\section{ROSS ICE SHELF FIELD SITE AND GPS DEPLOYMENT}

Our main field site was Nascent Iceberg, at the front of the Ross Ice Shelf $\left(78.1^{\circ} \mathrm{S}, 178.5^{\circ} \mathrm{W}\right.$; Fig. 1). This site is near a large rift that is the extension of the iceberg-detachment rift from which iceberg B15 calved in March 2000 (MacAyeal and others, 2008). The rift is presumed to be continuing to propagate westward, and will eventually link with the ice front, to create a new $20 \mathrm{~km} \times 40 \mathrm{~km}$ iceberg (hence the term 'nascent'). To determine if diurnal-scale temporal variations might have a role in its propagation, we established two GPS stations, $4.2 \mathrm{~km}$ apart, on either side of the rift, and named them Nascent North (NN) and Nascent South (NS). We deployed a third station (R13; Fig. 1) at the approximate location that was occupied in 1976 and 1977 by a pre-GPS geoceiver associated with the Ross Ice Shelf Geophysical and Glaciological Survey (Bentley and others, 1979). At each station, a dual-frequency GPS receiver sampled data continuously every $15 \mathrm{~s}$. Stations NS and R13 were occupied for a 21 day period between 29 October and 21 November 2005. Station NN only collected data for 16 days due to logistical constraints.

\section{GPS DATA PROCESSING}

Our field site is $>300 \mathrm{~km}$ from the nearest permanent GPS reference station, so we analyzed the data using a kinematic Precise Point Positioning (PPP) approach, as outlined by King and Aoki (2003) using GIPSY v4.04 (Webb and Zumberge, 


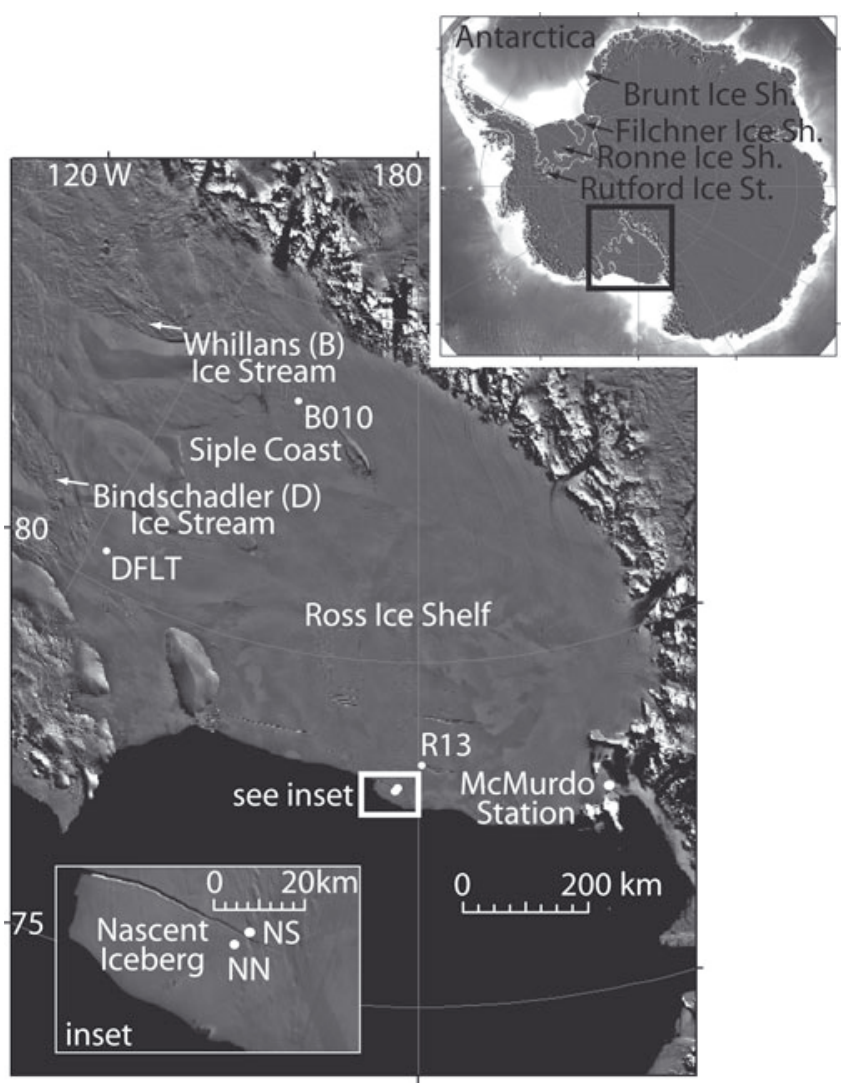

Fig. 1. Location map of our field site near the Ross ice front, showing the three GPS stations, NN, NS and R13. Background image is Moderate Resolution Imaging Spectroradiometer (MODIS) Mosaic of Antarctica (MOA) (Scambos and others, 2007).

1995). Kinematic data analysis is essential to avoid spurious tidal signals appearing in the coordinate time series (King, 2004). We estimated site positions every $5 \mathrm{~min}$. We modeled both solid-Earth tides and ocean-tide loading displacements, leaving systematic errors at tidal periods with magnitude no more than $\sim 10 \mathrm{~mm}$ (King and others, 2008). We cleaned the resulting coordinate time series based on the GIPSY formal errors. We eliminated $\sigma$ values $>0.2 \mathrm{~m}$ for the vertical and $>0.02 \mathrm{~m}$ for the easting and northing time series. The final data-processing steps included low-pass filter smoothing (to eliminate timescale variability, both real and associated with instrument error, with periods $\leq 15 \mathrm{~min}$ ) and detrending (to remove the large mean displacement of the station associated with mean, time-invariant ice-shelf flow). Corrections for horizontal displacements relative to the neutral (mid-)plane of the ice shelf resulting from ice-shelf flexure were not made, as these are considered to be second-order, given the large length scale of tidal flexure near the ice front. We extracted the time-varying horizontal velocities of the three stations from the cleaned, smoothed and detrended data, using least squares to fit linear and harmonic terms, including major semi-diurnal and diurnal constituents. Brunt (2008) provides further details of the least-squares method used to fit tidal constituents for this study.

\section{RESULTS}

The time series of GPS displacements at the three stations are shown in Figure 2. Once the high-frequency variability was filtered from the data, the residual diurnal-scale variability was similar at all stations, implying the velocity variations are not associated purely with expansion and contraction of the rift (Fig. 2).

Upon closer inspection, the signals from NS and NN appear slightly different while those from NS and R13 are strikingly similar (Fig. 2), even though NS is geographically closer to NN (Fig. 1). We attribute this to the fact that both NS and R13 are located on the landward side of a detachment rift, whereas $\mathrm{NN}$ is located on the seaward side where shorttimescale effects (e.g. sea swell) can have an influence on the rift width (Bassis and others, 2007).

The time series indicate that the horizontal ice flow is strongly modulated at ocean tidal periods at all three stations. Furthermore, these motions are comparable to, or exceed, the daily mean flow of the ice shelf derived from long-term averages of GPS data.

Each station recorded a strong diurnal signal, consistent with a linear response to ocean tidal fields of the Ross Sea region (Williams and Robinson, 1979). In addition to this diurnal-scale variability, each station possesses a $\sim 14$ day amplitude variation that is likely to be due to the familiar spring-to-neap cycle associated with superposition of solar and lunar tidal forcing, but may also contain both long-period tidal effects (e.g. Gudmundsson, 2006) and the influence of non-linearity in the ice shelf's response to tidal forcing. This spring-to-neap cycle is most clearly evident in the vertical displacements (Fig. 2), and is present in the horizontal displacements and velocity magnitude (Fig. 3). The asymmetry of the amplitude envelope in horizontal velocity magnitude (evident for stations NN and DFLT in Fig. 3 by the relative uniformity of velocity minima compared to velocity maxima) is an intriguing property, suggestive of non-linearity in ice-shelf/ice-stream response to tide. This phenomenon requires longer-duration observations to better characterize the spring-to-neap cycles in all components of the ice motion and to differentiate these cycles from periodicities arising from other effects.

The 16 day observation period at Nascent Iceberg (station $\mathrm{NN}$ ) has a time mean horizontal ice-flow velocity of $2.99 \mathrm{~m} \mathrm{~d}^{-1}\left(1093 \mathrm{~m} \mathrm{a}^{-1}\right)(2 \sigma=0.05)$ with a velocity increase of $\sim 100 \%$ of the mean (Fig. 3, left panel). This fluctuation, which peaks at $5.98 \mathrm{md}^{-1}\left(2185 \mathrm{ma}^{-1}\right)$ during the spring tide, has a neap-tide minimum of $0.98 \mathrm{~m} \mathrm{~d}^{-1}\left(359 \mathrm{~m} \mathrm{a}^{-1}\right)$.

Our reoccupation of R13 in 2005 indicated that during our observation period the horizontal flow of the ice shelf had not changed (to within $1 \mathrm{~m} \mathrm{a}^{-1}$ ) in this near-ice-front location since it was last measured (Bentley and others, 1979) almost three decades earlier.

\section{DISCUSSION}

The character of the signal observed at Nascent Iceberg is similar to the signal observed at, and upstream of, the grounding zone of Bindschadler Ice Stream (Anandakrishnan and others, 2003). The signals at both locations vary sinusoidally in time with spring-neap cyclicity and with diurnal and semi-diurnal periods associated with the dominant tidal constituents of the Ross Sea (Fig. 3, center panel, and fig. 3 of Anandakrishnan and others, 2003). However, the magnitudes of the variations in the signals at Nascent Iceberg and Bindschadler Ice Stream are very different. Bindschadler Ice Stream has a time-mean horizontal ice-flow velocity of $1.22 \mathrm{~m} \mathrm{~d}^{-1}\left(400 \mathrm{~m} \mathrm{a}^{-1}\right)$ which increases to $\sim 1.65 \mathrm{~m} \mathrm{~d}^{-1}$ 

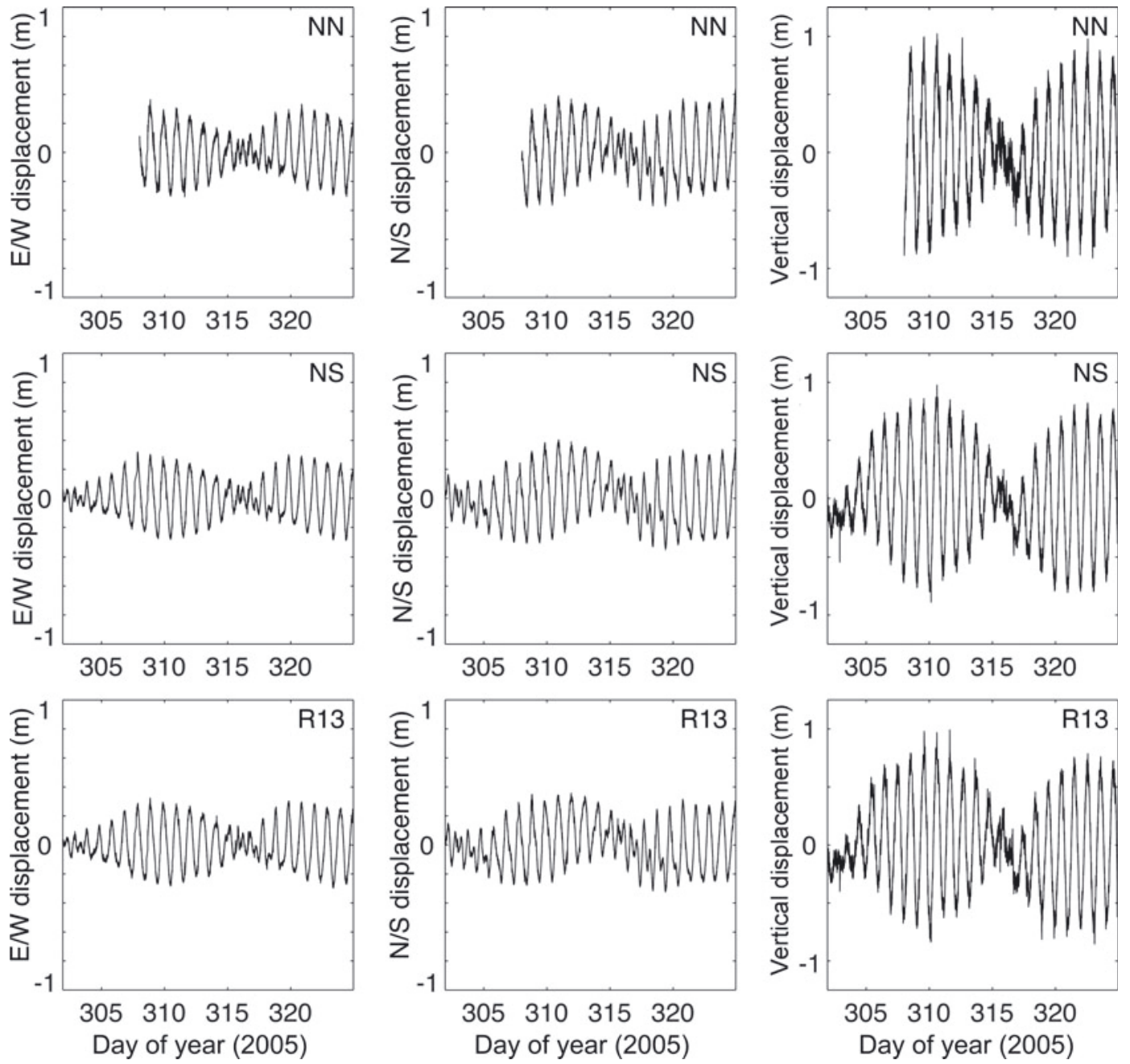

Fig. 2. Time series of displacements at the three GPS stations. Plots show filtered (cleaned, smoothed and detrended) displacements derived from the GPS observations (Brunt, 2008), in the easting (left column), northing (center column) and vertical (right column) directions for NN (top row), NS (middle row) and R13 (bottom row). Note the diurnal nature of the signal and the clear spring-neap tidal cycle, mostly evident in the larger displacements of the easting and vertical directions.

$\left(\sim 600 \mathrm{ma}^{-1}\right)$ during the spring tide (a velocity increase of $50 \%$ of the mean). However, the GPS observations at Nascent Iceberg indicate that the velocity increases by $100 \%$ of the mean (Fig. 3, left and center panels).

In contrast to the similarities with Bindschadler Ice Stream, the character of the signal observed at Nascent Iceberg is dissimilar to the signal observed within the grounding zone of Whillans Ice Stream (Bindschadler and others, 2003), where GPS measurements reveal a quasi-periodic 'stick-slip' response to the tide (Fig. 3, right panel). The variation in the signals observed at these two ice streams has been attributed to basal conditions and the presence of 'sticky spots' on the bed beneath Whillans Ice Stream (Bindschadler and others, 2003; Winberry and others, 2009). However, the contrast of the observations in the ice streams to the character and magnitude of the signal observed at Nascent Iceberg remains unexplained.

The spring-neap variation observed at Nascent Iceberg is not to be confused with the fortnightly variation observed by Gudmundsson (2006, 2007) and Murray and others (2007) on Rutford Ice Stream. The variation at Nascent Iceberg is embodied by the well-known variation of the
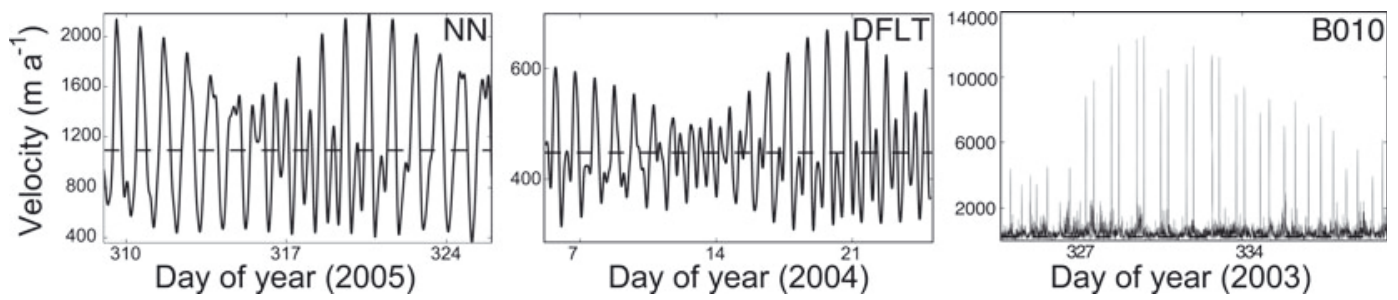

Fig. 3. Time series of ice-flow velocities (solid curves) showing fluctuation about the time mean (dashed line), for Nascent Iceberg (station NN, left), Bindschadler (site DFLT, center) and Whillans (site B010, right) Ice Streams, based on GPS data. Each time period spans at least a full spring-neap tide cycle. (Data for Bindschadler and Whillans Ice Streams, personal communication from R. Bindschadler, 2007.$)$ 
amplitude envelope of the diurnal and semi-diurnal tidal signal, whereas at Rutford Ice Stream there is a strong sinusoidal response with a $\sim 14$ day period. Mechanisms explaining the fortnightly variation at Rutford involve a nonlinear relationship to subglacial resistance (Gudmundsson, 2007). Thus, it would add further evidence of non-linear response in the ice-shelf/ice-stream system if these were expressed in the Nascent Iceberg data. The brevity of the data-collection periods precludes any attempt to either verify or deny the presence of a $\sim 14$ day cycle in the ice-shelf motion of the nature seen in the GPS records of Rutford Ice Stream flow (Gudmundsson, 2006, 2007).

The similarities between the diurnal signals at the ice front and those in the ice streams, each $>600 \mathrm{~km}$ away, suggest that the ice shelf is joined with the ice streams in a large, unified system that responds to the minute stress variations caused by ocean tide, which ultimately modulates horizontal flow. The observations we present here provide a preliminary view of this system, but remain insufficient to characterize more completely the nature of the ice shelf's response to tide over the large intervening distance between the ice front and grounding zone. Further research, both observational and numerical, is necessary. However, we speculate that the similarity in tidal signals between Nascent Iceberg and the ice streams suggests that the tide may be modulating flow over most of the $450000 \mathrm{~km}^{2}$ area of the Ross Ice Shelf. These observations are the first to suggest that the dynamics of floating ice well downstream of the grounding line may be linked to ice-stream flow.

\section{IMPLICATIONS}

Tidal modulation of the horizontal flow of an ice shelf was first discovered through GPS measurements on the Brunt Ice Shelf by Doake and others (2002). Gudmundsson (2007) also observed tidally modulated flow on Rutford Ice Stream and proposed that such modulation could be an endemic quality of entire ice-shelf/ice-stream systems. He reasoned that the intimate dependence of ice-stream flow on ocean tides could be a property of the larger, combined system of interdependent ice-shelf and ice-stream (including properties of the ice-stream subglacial bed) stress balance. It is important to investigate Gudmundsson's (2007) proposal, because, if it is true, it further illuminates the roles sea-level fluctuations and ice-shelf back pressures (Thomas, 1979) can have on cross-grounding-line mass flux of the Antarctic ice sheet.

Our work on the Ross Ice Shelf confirms Gudmundsson's (2007) proposition while simultaneously illustrating certain unexpected complexities in the results. Our observations demonstrate that the Ross Ice Shelf possesses horizontal flow fluctuations paced by the diurnal and semi-diurnal tides, by the spring-to-neap cycle and possibly by long-period tides. This result is consistent with the tidal fluctuations observed at, and upstream of, the grounding lines of the ice streams that feed the ice shelf (Anandakrishnan and others, 2003; Bindschadler and others, 2003). The unexpected aspects of our results are: (1) the strong amplification of tidal horizontal ice motion between the ice-stream grounding lines, where tidal forcing is thought to be most influential, and the ice front, where tidal forcing is expected to be least influential, and (2) the absence of tidally triggered stick-slip motions in the ice shelf due to the Whillans Ice Stream (e.g. Winberry and others, 2009). These unexpected properties of the ice- stream/ice-shelf system imply: (1) that the ice shelf as a whole, and not simply the grounding line, is where tidal forcing of the stress balance is most active and (2) that there is considerable elastic resilience in the ice shelf that is capable of absorbing and distributing the stress perturbations imposed by the short-lived, impulsive slip events of the Whillans Ice Stream.

An understanding of the dynamics associated with Siple Coast ice-stream flow, and how that links with the flow of the Ross Ice Shelf, is fundamental for model development that addresses the mass balance of the West Antarctic ice sheet and its response to climate change. Therefore, there is a critical need for models that accurately characterize the processes that modulate horizontal flow of the icestream/ice-shelf/ocean system. The disparities in the tidal modulations we have observed in different parts of this system, however, present a serious challenge to existing models of ice-stream/ice-shelf flow that treat the ice system using a viscous, laminar-flow description. While simple elastic models have addressed the stick-slip motion in Whillans Ice Plain, in the vicinity of site B010 (Fig. 1; Winberry and others, 2009), how this signal is damped before reaching the front of the ice shelf remains unclear. Furthermore, how smooth sinusoidal time variations in horizontal flow observed at other ice-stream grounding lines are amplified at the seaward front of the ice shelf also remains unclear. The GPS observations at Nascent Iceberg described here provide critical constraints for extending the modeling efforts into realms capable of explaining these complexities. Our measurements are preliminary. When combined with previous measurements of ice-shelf response to tide at the grounding zone, they fail to cover the large intervening region between the grounding zone and ice front. To advance further, a more complete field campaign, involving GPS and also tiltmeters (to describe kinematic effects associated with flexure), addressing the intervening region is recommended.

\section{ACKNOWLEDGEMENTS}

We thank R.A. Bindschadler, H. Gudmundsson, L. Copland, E.B. O'Donnell, J.E. Thom, L.M. Cathles, O. Sergienko, M. Okal, T. Wagner, Kenn Borek Air, the University Navstar Consortium (UNAVCO) and the Raytheon Polar Services Company (RPSC) for data, data analysis and field support. We thank three anonymous reviewers of this and previous versions of the manuscript. The University of Chicago portion of this work was supported by US National Science Foundation grant OPP-0229546; the SIO portion of this work was supported by NASA grant NNG05GR58G.

\section{REFERENCES}

Anandakrishnan, S., D.E. Voigt, R.B. Alley and M.A. King. 2003. Ice Stream D flow speed is strongly modulated by the tide beneath the Ross Ice Shelf. Geophys. Res. Lett., 30(7), 1361. (10.1029/2002GL016329.)

Bassis, J.N. and 7 others. 2007. Seismicity and deformation associated with ice-shelf rift propagation. J. Glaciol., 53(183), 523-536.

Bentley, C.R., J.W. Clough, K.C. Jezek and S. Shabtaie. 1979. Ice-thickness patterns and the dynamics of the Ross Ice Shelf, Antarctica. J. Glaciol., 24(90), 287-294.

Bindschadler, R.A., M.A. King, R.B. Alley, S. Anandakrishnan and L. Padman. 2003. Tidally controlled stick-slip discharge of a West Antarctic ice stream. Science, 301(5636), 1087-1089. 
Brunt, K.M. 2008. Tidal motion of the Ross Ice Shelf and its interaction with the Siple Coast Ice Streams, Antarctica. (PhD thesis, University of Chicago.)

Doake, C.S.M. and 6 others. 2002. Tide-induced lateral movement of Brunt Ice Shelf, Antarctica. Geophys. Res. Lett., 29(8), 1226. (10.1029/2001GL014606.)

Gudmundsson, G.H. 2006. Fortnightly variations in the flow velocity of Rutford Ice Stream, West Antarctica. Nature, 444(7122), 1063-1064.

Gudmundsson, G.H. 2007. Tides and the flow of Rutford Ice Stream, West Antarctica. J. Geophys. Res., 112(F4), F04007. (10.1029/2006JF000731.)

King, M. 2004. Rigorous GPS data-processing strategies for glaciological applications. J. Glaciol., 50(171), 601-607.

King, M. and S. Aoki. 2003. Tidal observations on floating ice using a single GPS receiver. Geophys. Res. Lett., 30(3), 1138. (10.1029/2002GL016182.)

King, M.A., C.S. Watson, N.T. Penna and P.J. Clarke. 2008. Subdaily signals in GPS observations and their effect at semiannual and annual periods. Geophys. Res. Lett., 35(3), L03302. (10.1029/2007GL032252.)

Legrésy, B., A. Wendt, I.E. Tabacco, F. Rémy and R. Dietrich. 2004. Influence of tides and tidal current on Mertz Glacier, Antarctica. J. Glaciol., 50(170), 427-435.

MacAyeal, D.R., M.H. Okal, J.E. Thom, K.M. Brunt, Y.-J. Kim and A.K. Bliss. 2008. Tabular iceberg collisions within the coastal regime. J. Glaciol., 54(185), 371-386.
Mercer, J.H. 1968. Antarctic ice and Sangamon sea level. IASH Publ. 79 (General Assembly of Bern 1967 - Snow and Ice), 217-225.

Murray, T., A.M. Smith, M.A. King and G.P. Weedon. 2007. Ice flow modulated by tides at up to annual periods at Rutford Ice Stream, West Antarctica. Geophys. Res. Lett., 34(18), L18503. (10.1029/2007GL031207.)

Scambos, T.A., T.M. Haran, M.A. Fahnestock, T.H. Painter and J. Bohlander. 2007. MODIS-based Mosaic of Antarctica (MOA) data sets: continent-wide surface morphology and snow grain size. Remote Sens. Environ., 111(2-3), 242-257.

Thomas, R.H. 1979. Ice shelves: a review. J.Glaciol., 24(90), 273-286.

Vaughan, D.G. 1995. Tidal flexure at ice shelf margins. J. Geophys. Res., 100(B4), 6213-6224.

Webb, F.H. and J.F. Zumberge. 1995. An introduction to GIPSY/OASIS II. Pasadena, CA, California Institute of Technology. Jet Propulsion Laboratory. (JPL Tech. Doc. D-11088.)

Wiens, D.A., S. Anandakrishnan, J.P. Winberry and M.A. King. 2008. Simultaneous teleseismic and geodetic observations of the stick-slip motion of an Antarctic ice stream. Nature, 453(7196), 770-774.

Williams, R.T. and E.S. Robinson. 1979. Ocean tide and waves beneath the Ross Ice Shelf, Antarctica. Science, 203(4379), 443-445.

Winberry, J.P., S. Anandakrishnan, R.B. Alley, R.A. Bindschadler and M.A. King. 2009. Basal mechanics of ice streams: insights from the stick-slip motion of Whillans Ice Stream, West Antarctica. J. Geophys. Res., 114(F1), F01016. (10.1029/2008JF001035.)

MS received 20 August 2009 and accepted in revised form 30 December 2009 